\title{
ASSESSMENT OF NEUTRAL ATMOSPHERIC DELAY PREDICTIONS BASED ON THE TEMPORAL RESOLUTION OF AN ATMOSPHERIC MODEL
}

\author{
Tayná Aparecida Ferreira Gouveia ${ }^{1}$ - ORCID: 0000-0003-1140-752X \\ Luiz Fernando Sapucci - ORCID: 0000-0001-8420-8033 \\ João Francisco Galera Monico ${ }^{1}$ - ORCID: 0000-0003-4101-9261 \\ Daniele Barroca Marra Alves ${ }^{1}$ - ORCID: 0000-0002-9033-8499
}

\footnotetext{
${ }^{1}$ Universidade Estadual Paulista - UNESP, Faculdade de Ciência e Tecnologia, Departamento de Cartográfica, Presidente Prudente - SP, Brasil.

E-mail: tayna.fgouveia@gmail.com; galera.monico@unesp.br; danibarroca@unesp.br

\author{
${ }^{2}$ Instituto Nacional de Pesquisas Espaciais - INPE, Centro de Previsão de Tempo e Estudos Climáticos/Divisão de \\ Desenvolvimento e Modelagem, Cachoeira Paulista -SP, Brasil. \\ E-mail: luiz.sapucci@inpe.br
}

Received in $01^{\text {st }}$ February 2019

Accepted in $15^{\text {th }}$ October 2019

\begin{abstract}
:
In Global Navigation Satellite Systems (GNSS), the effects of neutral atmosphere in electromagnetic signal propagation impacts directly on the quality of the final estimated position, leading to errors in the metric order. Using an atmospheric model is a good strategy to minimize these errors, because it becomes possible to obtain a neutral atmospheric delay with the same spatial and temporal resolution, taking into consideration particularities of the atmosphere treated by a numerical model. The regional model of the Center for Weather Forecasting and Climate Studies (CPTEC) used in this paper has a spatial resolution of $15 \mathrm{~km}$ and a temporal resolution of 3 hours. Usually, the delay prediction of 3 hours is interpolated in time to GNSS applications and this can influence the quality of the values obtained in each interpolated epoch. Higher temporal resolutions can lead to lower errors in the final position. In this paper, the quality of delay predictions is evaluated for this atmospheric model with resolutions of 6 and 3 hours. The estimated delay, derived from meteorological data in the same location as the geodetic data, is considered as "truth". The temporal resolution of 3 hours shows better results than using 6 hours, particularly for the hydrostatic component in the initial prediction period, RMSE of $1.25 \mathrm{~cm}$ was reduced to $0.2 \mathrm{~cm}$ in NEIA station.
\end{abstract}

Keywords: Neutral atmospheric delay modeling; GNSS positioning; Atmospheric model.

How to cite this article: GOUVEIA, T. A. F. ; SAPUCCI, L. F.; MONICO, J. F. G.; ALVES, D. B. M. Assessment of neutral atmospheric delay predictions based on the temporal resolution of an atmospheric model. Bulletin of Geodetic Sciences. 26(1): e2020001, 2020 


\section{Introduction}

For meteorological applications the measurement of temporal oscillation of atmospheric components represents information for weather and climate predictions; for Geodetic applications the information can be used to infer the atmosphere impact on the Global Navigation Satellite Systems (GNSS) signal propagation. Regarding satellite positioning, if not treated properly, the atmosphere can affect the quality of the coordinates obtained from GNSS. It is therefore necessary to minimize such effects.

Radio signals transmitted by satellites are affected by the atmosphere, which causes a delay in the propagation time proportional to the total electron content and gases and water vapor. In geodetic sciences the atmosphere is normally divided into two layers: ionosphere, which is electrically charged and extends from 50 to $1000 \mathrm{~km}$ above the earth's surface, and the neutral atmosphere, that is electrically neutral but with an uneven distribution of gases and water vapor, extending from the surface up to $50 \mathrm{~km}$.

The errors caused by the ionosphere can be minimized by applying linear combinations (ion free) (Hofmann et al, 1992) or estimated during the data processing ( $\mathrm{Li}, \mathrm{X}$. et al 2013). The effect due to neutral atmosphere varies proportionally to the elements that compose this layer, which can be modeled (Seeber, 2003).

The neutral atmospheric delay may cause an error of high impact for applications requiring decimetric accuracy such as aviation and precision agriculture. In the zenith direction, the effect is called Zenith Total Delay (ZTD) and can be divided into two components due to neutral atmosphere composition: wet, composed by water vapor; and hydrostatic, composed by other gases. The hydrostatic component, Zenith Hydrostatic Delay (ZHD), can be determined based on the location and atmospheric pressure values, and represents $90 \%$ of ZTD, with a low variation during the day. The wet component, Zenith Wet Delay (ZWD), is obtained mainly from the humidity and temperature profiles. Although it is about $10 \%$ of ZTD, the ZWD has a decimeter level range and varies by season and time of year. The ZHD and ZWD equations are described in Spilker et al. (1994) and Sapucci (2001). The sum of these two components results in the ZTD. The ZTD should therefore be minimized in the geodesic positioning, and there are different techniques are proposed for this.

ZTD modeling using Numerical Weather Prediction (NWP) offers an alternative to minimize the effects of the neutral atmosphere in the GNSS satellite signals. The ZTD modeling process using NWP is proposed in Sapucci et al. (2004). In Brazil, the Center for Weather Forecasting and Climate Studies (CPTEC) of the Brazilian Institute for Space Research (INPE) has been operating regional NWP models that consider data from the South America region in their calculations. The NWP data are available at CPTEC/INPE website (ftp://ftp1.cptec.inpe.br/modelos/tempo/). These models are frequently updated as physical and dynamic improvements or refinements of spatial and temporal resolutions are developed (Mesinger et al. 2012). Eta has different characteristics in relation to other NWP models, in which should be highlighted its vertical coordinate ( $\eta$ - Eta) and the usage of the pressure normalization, where the surfaces (considered constant) are almost horizontal on both flat and mountains regions, which minimizes errors in atmospheric parameters computation (Mesinger, 1984).

Since 2004, CPTEC/INPE provides a ZTD/CPTEC product that makes ZTD predictions available, with the use of improved spatial and temporal resolution. Until early 2012 the Eta model was operational with a horizontal resolution of $20 \mathrm{~km}, 38$ vertical levels at every 6 hours (UTC). The Eta model was replaced by the regional model named Eta-15km, with a horizontal resolution of $15 \mathrm{~km}$, a vertical resolution of 42 levels, and a time resolution of 3 hours (UTC). It was expected that better quality in ZTD predictions would be obtained with this improvement of NWP models. The quality of ZTD prediction and its impact on GNSS positioning has been discussed by some authors: Differential Global Positioning System (DGPS) (Dalbelo et al., 2006); Analysis with network-based positioning and VRS (Virtual Reference Station) (Oliveira et al., 2014a, 2014b); Absolute positioning (Abreu et al., 2014). In Gouveia et al. (2014), a robust assessment is presented of the previous version of ZTD predictions, the Eta-20km. Another assessment of the Eta- $15 \mathrm{~km}$ was also carried out to verify the quality of the model in relation to climate and regional 
variations, reaching centimetric accuracy in GNSS positioning (Alves et al., 2015).

The papers cited have shown good quality of ZTD predictions. However, the influence of different time resolutions has not been investigated yet. In this paper, the evaluation has become possible with the use of the Eta$15 \mathrm{~km}$ model in ZTD predictions with 3 hour resolution to simulate a 6-hour file, removing the intervals of 3 hours and considering only the predictions of 6 to 6 hours. ZTD is directly correlated with the variations of meteorological parameters. The hydrostatic component is influenced by temperature and pressure, which has a lower variation throughout the day. The wet component is correlated with water vapor and achieves a higher variation within a few hours. For GNSS applications, modeling of the ZTD can be obtained in shorter time intervals (e.g. epochs of 5 minutes) due to the variation of the atmosphere in a few hours. Thus, when a temporal interpolation for prediction data ( 3 hours) is carried out, the temporal resolution of the data can impact on the quality of the ZTD prediction for each interpolated epoch. For this reason, temporal resolution analysis is necessary to access this impact and quantifying it. The ZTD from NWP models with higher temporal resolution and adequate interpolation can provide more accurate results for GNSS positioning.

In this paper, the Eta model with improved time resolution was used to assess the ZTD. The stations used in the evaluation belong to the GNSS Network of São Paulo State, which has equipped some of its GNSS stations with meteorological sensors. This enables evaluation of the hydrostatic and wet components separately. It is also possible to evaluate the components on which the temporal resolution improvement has the greater impact. This paper is divided into four sections. Section 2 discusses the methodology and data used. The results are presented in section 3 and the conclusions in section 4 .

\section{Methodology}

The quality of the ZTD prediction obtained through the NWP model is assessed comparing the new time resolution with the ZTD estimated as a parameter in the processing of GNSS observables in the GOA-II software. Both methods and software are shown in section 2.1. The ZTD estimated is taken as a reference because of this higher accuracy (Sapucci, 2001). The interpolation between the ZTD predicted, available every 3 hours, and the ZTD estimated every 5 minutes, is carried out using the cubic spline interpolation, and it is therefore possible to evaluate the quality of the different temporal resolutions. Cubic spline functions are third degree polynomials with "pseudo-analytical" characteristics, which offer good approximation properties, convergence and stability (Alves, et al., 2005). This technique consists in dividing the interval of interest into several subintervals and to model the values as a function which changes smoothly in time. This function was chosen based on results reported in the previous works (Alves et al., 2005). The ZTD obtained from Eta-15km is available in the same file with predictions every 3 hours ( $0 \mathrm{~h}, 3 \mathrm{~h}, 6 \mathrm{~h}, 9 \mathrm{~h}, 12 \mathrm{~h}, 15 \mathrm{~h}, 18 \mathrm{~h}, 21 \mathrm{~h}$ and $24 \mathrm{~h}$ ). It is resampled to 6 -hourly intervals $(0 \mathrm{~h}, 6 \mathrm{~h}, 12 \mathrm{~h}, 18 \mathrm{~h}$ e 24h). The spline interpolation is performed every 5 minutes from 9 values, of $3 \mathrm{~h}$ each per day, and is resampled to 5 values (6h each). It is then possible to assess the ZTD, in the same files, with the same spatial resolution, for intervals of 3 and 6 hours, assessing only the temporal resolution.

\subsection{Methods and software used in the assessment}

The NWP model provides predictions of meteorological variables such as temperature, pressure, and humidity ( $\mathrm{T}, \mathrm{P}$ and $\mathrm{H}$ ) on a regular grid with a spatial and temporal resolution. The temporal resolution is associated with the frequency in which the values are available in the model of the integration interval. The NWP models can be divided by the area of coverage modeled, either global models covering the entire surface from the globe or regional models 
covering only parts of the earth's surface. Regional models generally have a better spatial resolution. The values observed for the meteorological variables are obtained in various locations on the globe in an irregular grid. The regular grid model, which is interpolated, can be interpreted as a matrix that is used by programs for integration in which a value is calculated for each cell. The ZTD/NWP model is available at http://satelite.cptec.inpe.br/zenital/.

The reference ZTD is estimated from the GPS Inferred Positioning System (GIPSY); Orbit Analysis and Simulation Software - OASIS II (GOA-II) (Gregorius, 1996). The processing strategy applied in this paper uses the GOA-II and the precise point positioning (PPP) method, considering two observables available on two carrier frequencies of the GPS satellite signals. The first-order ionospheric effects are corrected by applying the ionospheric-free linear combination observations at 5-minute intervals, with a mask of 10 degree elevation angle. The ZTD is obtained by GPS data processing. The ZHD is known and the ZWD is estimated using stochastic processes, such as, random walk to ZWD (Gregorius, 1996) and the mapping function VMF1. The quality of the ZTD estimated with GOA-II is considered as "truth" since it is equivalent with measurements from radiosondes (Sapucci, 2005). The evaluation of the quality of the ZTD obtained through the NWP is assessed by the quality of the ZTD estimates from GOA-II.

\subsection{Data used in the assessment}

The periods considered in this paper are the months of January and July 2014: January is used as a quality assessment and the two concomitant months (January-summer and July-winter) are used to observe whether the variation in the weather also impacts on the data in the temporal resolution. Assessment of the impact of seasonality on ZTD predictions can be found in Gouveia (2014). The GNSS sites evaluated are selected from the stations with available meteorological data in the state of São Paulo (Sapucci, 2010; Monico, 2006). Those with both types of data available are the: SPAR, SPCA, NEIA, OURI, PPTE, ROSA, SJRP and UBA1 stations. The distribution of stations is presented in Figure 1.

The input files used in this assessment are:

- Data from the receivers in Receiver Independent Exchange format (RINEX format). These files are edited

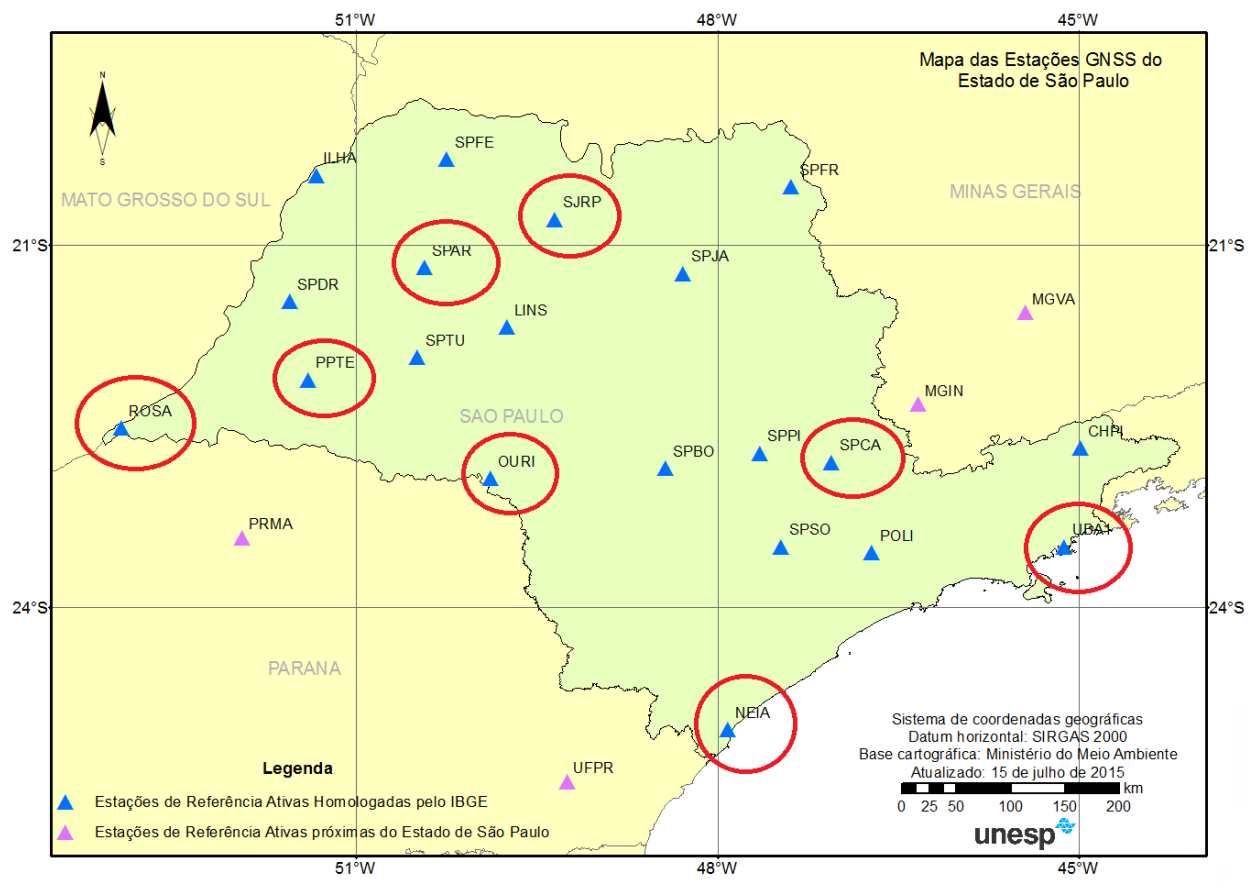

Figure 1: Location of the GNSS-SP stations used in this work.

Source: Adapted from https://www.fct.unesp.br/\#!/pesquisa/grupos-de-estudo-e-pesquisa/gege//gnss-sp-network2789/. 
with Translation, Editing and Quality Checking (TEQC) to obtain meteorological parameters;

- Daily ZTD files at 5 minutes interval obtained by post-processing PPP with the GOA-II software and the outputs per station;

- ZTD prediction data from the regional model Eta- $15 \mathrm{~km}$, with a time interval of 3 hours.

\subsection{Applied methodology}

The neutral atmospheric delay estimated by GOA-II is the total component ZTD. Meteorological files provide pressure $(\mathrm{P})$, temperature $(\mathrm{T})$ and humidity $(\mathrm{H})$ at each station. They must have the same time interval as the ZTD. The equation that relates the ZTD with the atmospheric variables can be found in Spilker et al. (1994) and Sapucci (2001).

The ZWD is obtained from the difference between the estimated ZTD and the ZHD is computed from surface measurements of $P, T$ and $H$. The delay predicted by the NWP is obtained from the predicted variables $(P, T$ and $H)$ using the Eta- $15 \mathrm{~km}$ model with separate outputs at grid model range in the wet and hydrostatic components. The ZTD data for the wet and hydrostatic components are obtained from the website: http://satelite.cptec.inpe.br/ zenital/. An interpolation program is available at the same address, making it possible to obtain the ZWD and ZHD values for the specific location within the range of the Eta-15 km model.

Based on the estimated and predicted data for the same components and periods, the assessment is carried out considering:

- cubic spline to predicted values of 3 and 6 hours and estimated value every 5 minutes for the ZHD and ZWD components;

- statistical analysis between the reference value and predictions at 3-hourly intervals and for predictions at 6-hourly intervals.

\section{Results and analysis}

The ZTD assessment is presented in this section with the prediction in relation to temporal resolution. An example with the spline interpolation for one day and two stations is given in section 3.1. In section 3.2, the impact of temporal resolution is evaluated over a month. Section 3.3 presents an average assessment considering all stations. The last sub-section shows the impact of seasonality in the different time resolutions.

\subsection{Spline Interpolation of different resolutions}

In order to show the interpolation of the ZTD predictions performed, the data of one day $(01 / 30 / 2014)$ is selected since it describes the average behavior observed, representing the difference between temporal resolutions for the NEIA station. In Figure $2 a$ the ZHD and Figure $2 b$ in ZWD are shown. The values of the ZTD prediction for NWP, every 3 hours, used for the spline interpolation, are highlighted by yellow circles. It can be seen from the results that the 3-hour resolution for ZHD is more consistent when compared with the reference values estimated by GPS observations, especially in the initial period of the first 3 hours forecast, and in the last hours. The 6-hour resolution on the hydrostatic component presents variations at the beginning of the day in the order of $9 \mathrm{~mm}$, and $4 \mathrm{~mm}$ at the end 


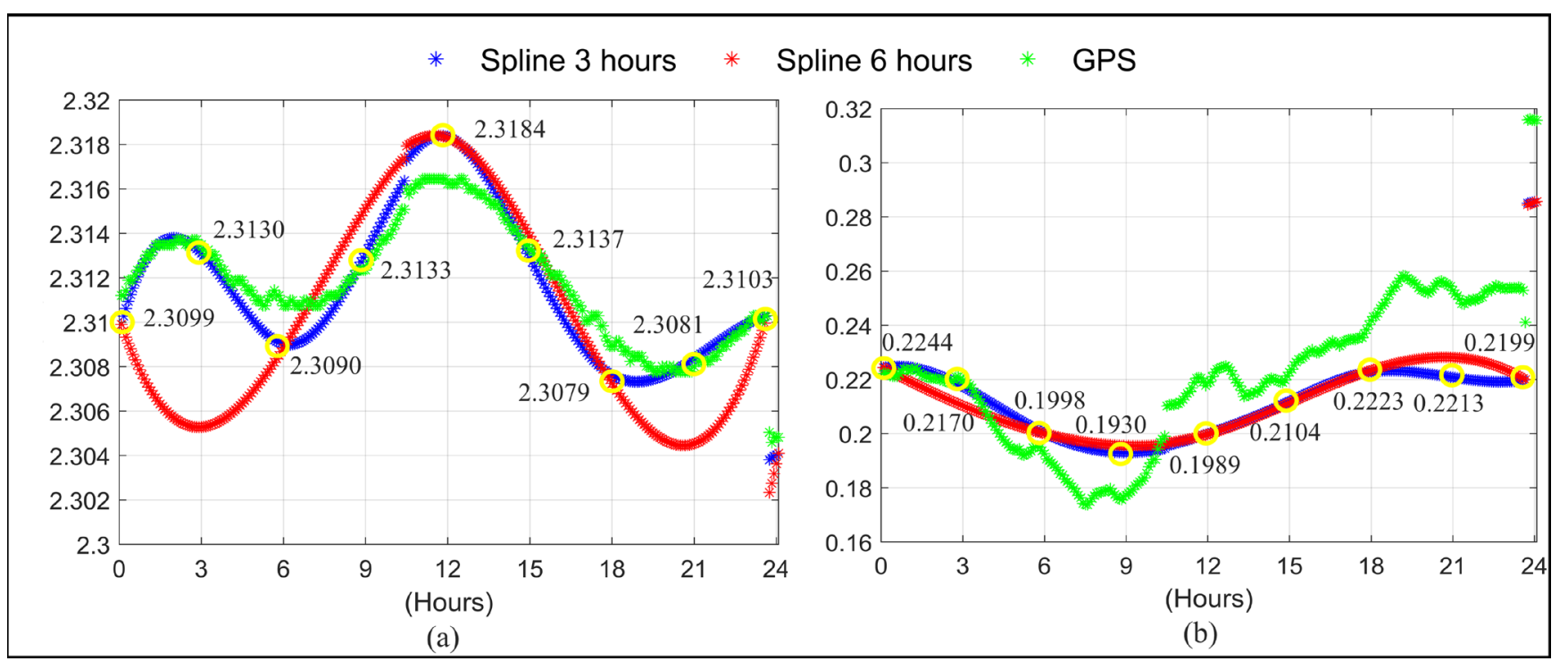

Figure 2: Spline 3h, and $6 \mathrm{~h}$ of NWP and $5 \mathrm{~min}$ from GOA-II for NEIA station. The (a) ZHD components (m), and (b) ZWD (m). Day 01/30/2014. Yellow circles represent the values predicted every 3 hours used for spline interpolation.

of the day. Concerning the wet component, this provides a ZWD consistent with the estimated value in the initial 3 hours, but the wet component has not presented significant improvement in the period of the day (after $3 \mathrm{~h}$ ) in either resolution ( $3 \mathrm{~h}$ and $6 \mathrm{~h}$ ).

\subsection{Assessment of temporal resolution}

Two stations are selected to assess the ZHD and ZWD components over one month (January 2014). The NEIA station (Figure $3 a, b$ ) is chosen because of its similar behavior to the other stations. The UBA1 station (Figure $3 c, d$ ) is also selected because it is different from the others. The statistics presented are: Bias, Standard Deviation (SD) and Root Mean Square Error (RMSE) for the hours of the day, assessing the quality of spline time resolution of 3 hours compared to 6 hours. Both interpolations are evaluated from estimates of ZTD from GOA-II.

Figure 3 presents the statistics for the NEIA station. The highest RMSE was observed from the ZHD splines (Figure 3a) with a temporal resolution of 6 in the 3 hours forecast. The highest difference between the 6 and 3 hour temporal resolution is in the initial period of the first 3 hours forecast in which the new temporal resolution of 3 hours improves in accuracy by $1,06 \mathrm{~cm}$ in the initial prediction period, which impacts on the quality of the predictions of ZHD. In the later prediction hours (21h-24h), the improvement using a 3-hour temporal resolution is $0.35 \mathrm{~cm}$ in the RMSE. Figure $3 \mathrm{~b}$, shows that the ZWD RMSE has oscillation. The biggest difference is in the order of $0.5 \mathrm{~cm}$ in the first hours of prediction, and improves in the 6-hour temporal resolution, in the later hours the two temporal resolutions have similar results, with an RMSE under $0.35 \mathrm{~cm}$.

Figure 3 (down) presents the statistics for the UBA1 station, which has lower values compared to NEIA, mostly in relation to the ZHD component (Figure 3c). The most significant difference is at the 3 hour mark (UTC), where the bias is $-0.143 \mathrm{~cm}$ for the 3-hour temporal resolution and $-0.287 \mathrm{~cm}$ for the 6 hour one, with RMSE of $0.276 \mathrm{~cm}$ for 3-hour resolution compared to $0.3577 \mathrm{~cm}$ of 6 hours spline. In Figure 3d, the ZWD component has a significant difference of $3.5 \mathrm{~cm}$ for the bias, between NEIA and UBA1, in the 3 hour prediction interval. The 6 -hour resolution has a better result of $0.23 \mathrm{~cm}$ in relation to the 3-hour resolution at the 3-hour mark. However, in the 21st predicted hour, the spline for the resolution of 3 hours has an improvement of $0.6 \mathrm{~cm}$. 


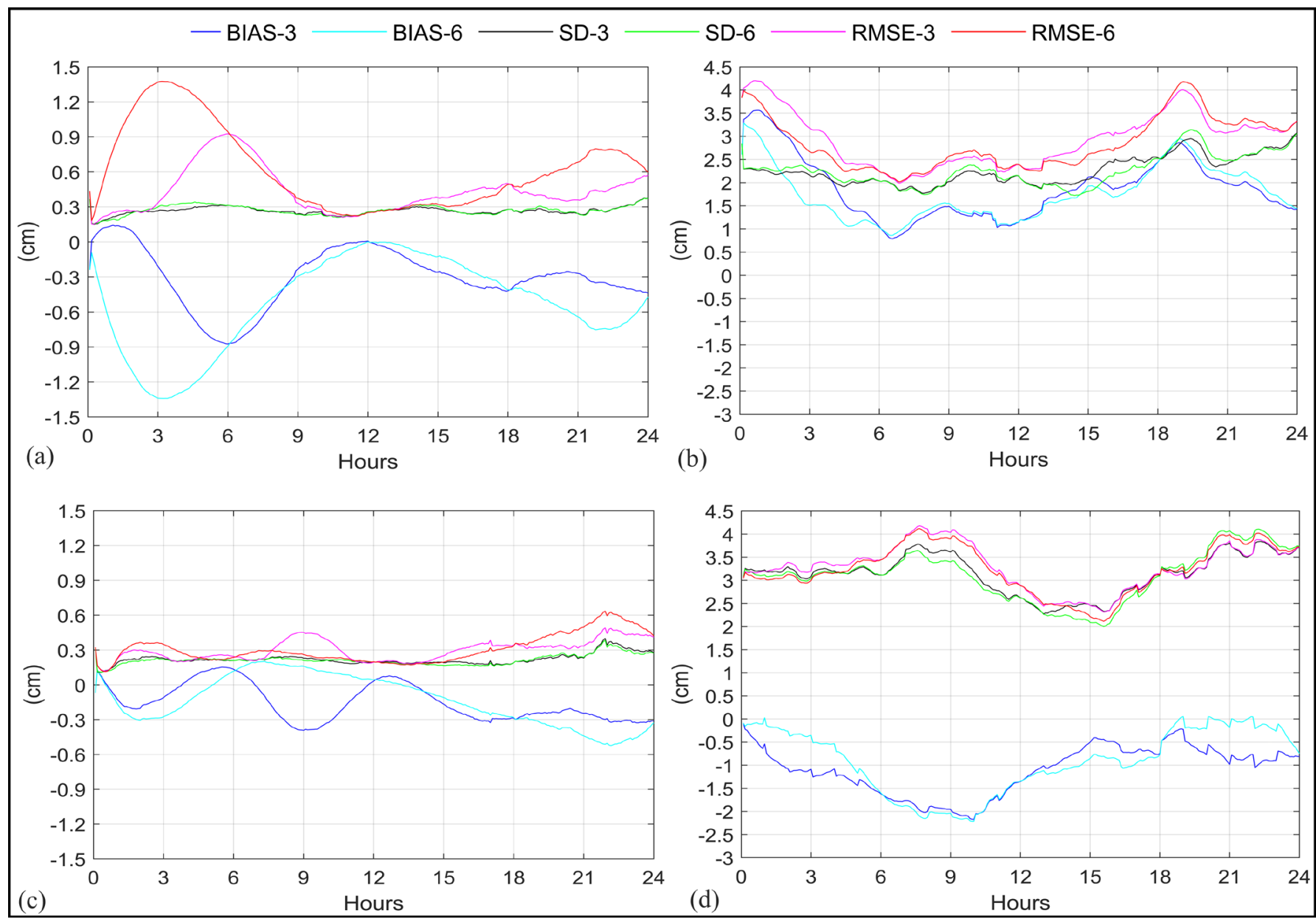

Figure 3: Bias, SD and RMSE of the ZHD on the left, Bias, SD and RMSE of the ZWD on the right, both January 2014 for hours of the day, the splines obtained from the predictions of 3 and 6 hours for the ( $a$ and $b$ ) NEIA and (c and

d) UBA1 stations.

The increase in temporal resolution from 6 to 3 hours therefore improves the ZHD component, for the investigated case. More analysis should be done to generalize and quantify the assumption. The quality of the ZWD is not well characterized. Although small, the 3-hour temporal resolution presented better results than the 6 hour one. In addition, the bias presented large differences in the ZHD and ZWD components in relation to the stations. This result should be further investigated.

\subsection{Average assessment}

In order to obtain an overview of the temporal resolution quality for the stations in São Paulo State, an assessment of the new temporal resolution ( 3 hour) is carried out using the RMSE estimated for each station in the month of January. Figure 4a shows the ZHD component and the improvement can be seen presented by the 3-hour resolution compared to the 6-hour, ranging from the west of the state to the Southeast $(0.2 \mathrm{~cm}$ to $0.01 \mathrm{~cm})$. In the ZWD component (Figure $4 \mathrm{~b}$ ), using a temporal resolution of 6 hours, the majority of assessed stations show better RMSE than the 3-hour temporal resolution, except for the SPCA and UBA1 stations, which present higher and equal RMSE, respectively.

The greatest improvement presented by the new temporal resolution can be observed in the ZHD component, in the order of $0.19 \mathrm{~cm}$. It may be noted that the ZWD component with the new resolution shows $-0.11 \mathrm{~cm}$. This 


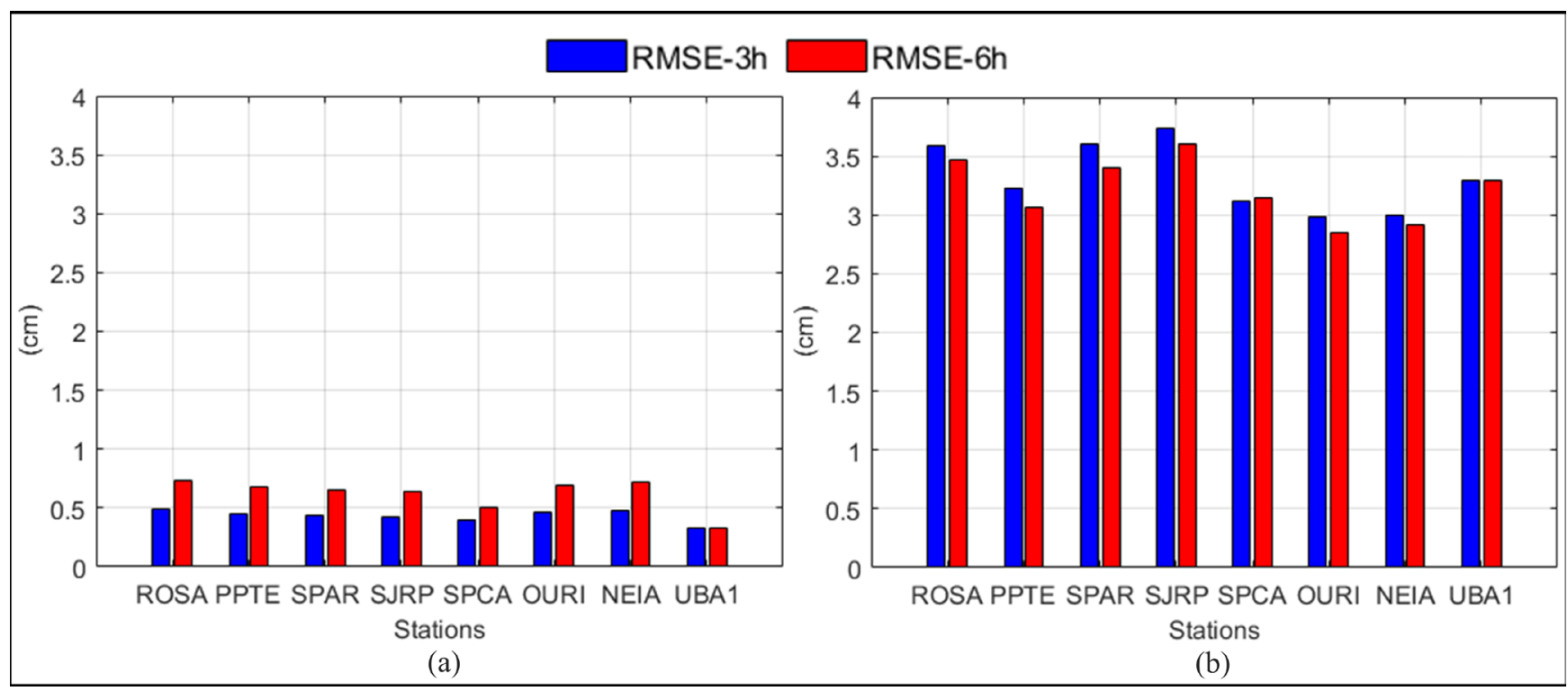

Figure 4: Average RMSE seasons assessed for the month of January 2014, the ZHD (a) and ZWD (b), considering the splines of 3 and 6 hours, the stations assessed in the west to southeast of São Paulo State.

shows that the significant gain with a new resolution is in the ZHD component, highlighting the ROSA, SPAR, SJRP, OURI, and NEIA stations. Concerning the ZWD component, the results of the $6 \mathrm{~h}$ resolution are better in most of the stations, SPCA being an exception. Due to high water vapor variability, improvements on the temporal resolution is not enough to generate positive impact in the ZWD estimates, which requires improvements in the spatial and temporal resolution, simultaneously. Therefore, further investigations should be done in the near future using NWP products that provide these requirements.

\subsection{Impact of summer and winter in the quality of $\mathbf{3}$ hours temporal resolution}

The NWP models show different performances representing the atmosphere at different times of the year due to higher atmospheric variability in the austral summer (January) and less variation in the austral winter (July). In Gouveia, et. al., (2014), the impact of seasonality in the ZTD was assessed in 10 stations in Brazil where the RMSE showed to be higher in summer, varying according to the location of the station.

The two components (ZHD, ZWD) of the ZTD can be analyzed separately, because of the meteorological stations next to GNSS stations. Figure 5 present the RMSE relative to ZHD and ZWD for the 3-hour time resolution for NEIA (higher RMSE in Figure 4a) and UBA1 (lower RMSE in Figure 4a and equal for both splines and components) stations considering the months of January and July. The NEIA station was chosen because of its similar behavior to the other stations. The UBA1 station was also chosen because its results showed greatest discrepancy.

Figure 5.a shows the effect of seasonality on the quality of ZHD for the NEIA station, in which July shows lower values (not exceeding $0.4 \mathrm{~cm}$ ) than January (minimum of the $0.35 \mathrm{~cm}$ ). The first day has a difference of $0.6 \mathrm{~cm}$ in the RMSE between January and July. Figure $5 \mathrm{~b}$ shows the effect of the seasonality in the ZWD component, it can be seen that the variation between summer and winter has a lower range, compared to the ZHD component. The biggest differences, between January and July, are for the days 4 and 9 to 15 , which have a maximum of $2 \mathrm{~cm}$. It should also be noted that it is not possible to find a pattern on the ZWD values.

For the UBA1 station, located on the northern coast of the state, (Figure $5 \mathrm{c}$ ) the ZHD has a $0.6 \mathrm{~cm}$ maximum value in January, but July does not exceed $0.4 \mathrm{~cm}$. These values are lower than for the NEIA station. In Figure $5 \mathrm{~d}$ a 


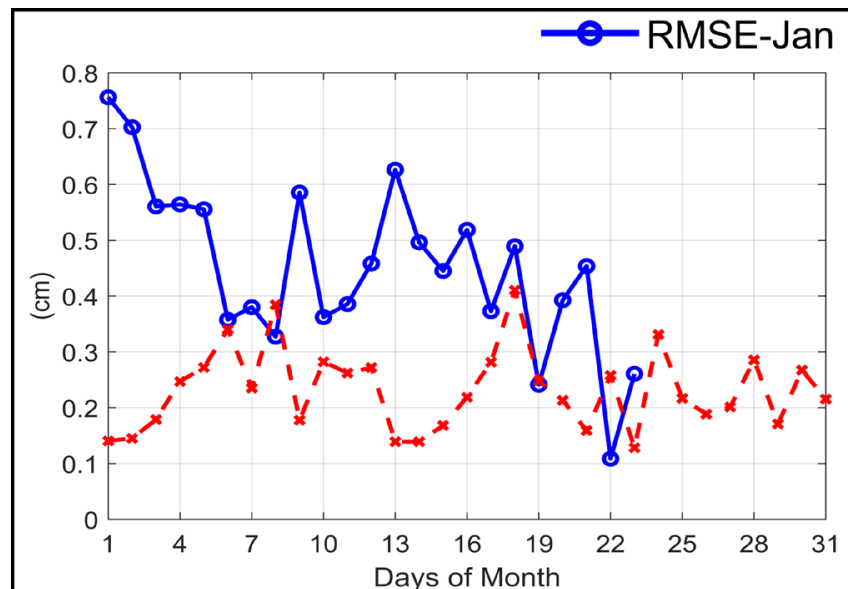

(a)

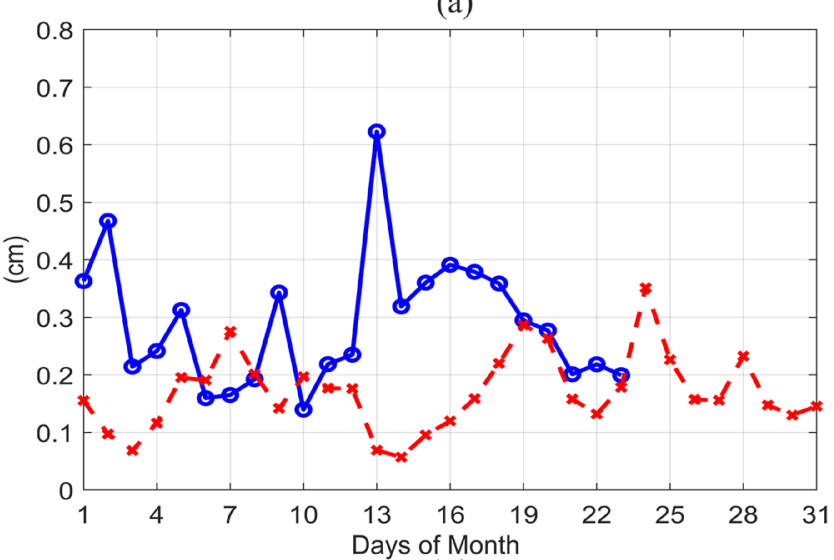

(c)

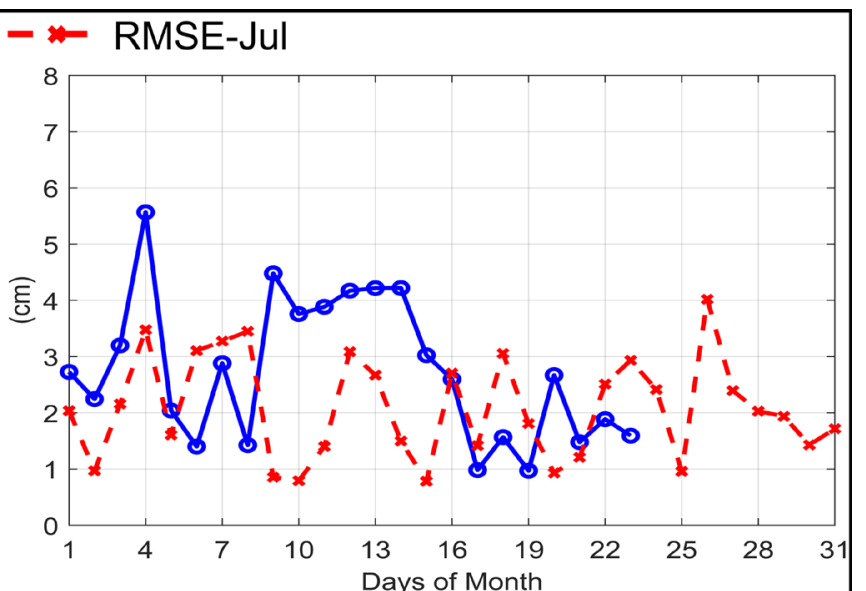

(b)

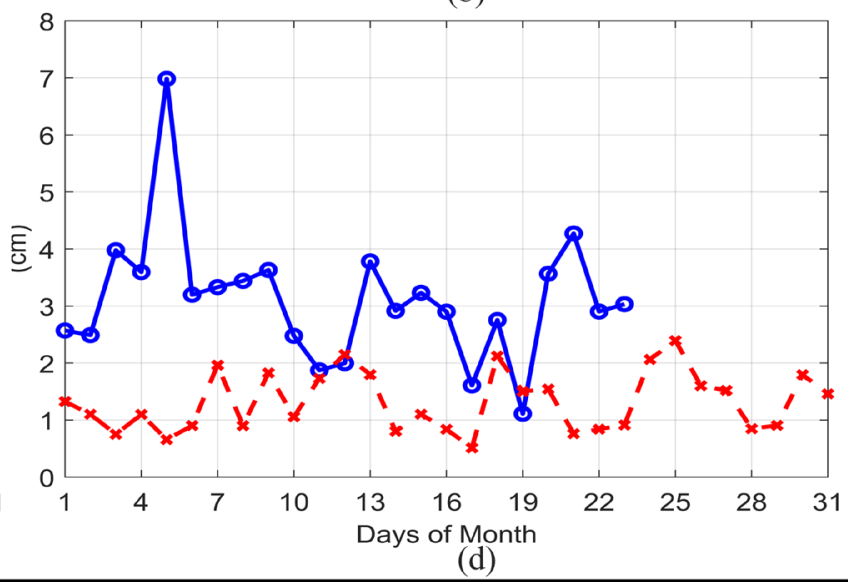

Figure 5: RMSE per day for January and July 2014, of the ZHD (on the left), and of the ZWD (on the right) to resolution $3 \mathrm{~h}$, for the ( $\mathrm{a}$ and $\mathrm{b}$ ) NEIA and (c and d) UBA1 stations.

larger impact of seasonality can be observed in the ZWD for the UBA1 station, ranging from 1 to $7 \mathrm{~cm}$ in January, compared to July, with an RMSE going from 0.5 to $2.5 \mathrm{~cm}$. In the ZWD component, it can be seen that the 5 days have been influenced by outliers, but as a general result, it is possible to observe a pattern in the accuracy of the ZWD prediction: January presenting a higher RMSE than July.

\section{Final considerations}

This work describes the assessment of higher temporal resolution and its impact on the prediction of ZTD. It has been possible to obtain predictions at 3 and 6 hours intervals with the same spatial resolution using the model Eta-15 km. The prediction of 3 and 6 hours has been interpolated to 5 -minute intervals with the use of cubic spline interpolation, making it possible to compare it with the ZTD estimation from GPS observations. The GNSS sites evaluated were: SPAR, SPCA, NEIA, OURI, PPTE, ROSA, SJRP and UBA1 stations, because these stations had meteorological data available. The choose period was January (summer) and July (winter).

The greatest impact on ZHD predictions occurred during the first 3 hours of prediction, in all stations and periods evaluated (Figure 2a, Figure 3a, Figure 3c and Figure 4a), which is important because it influences other predictions throughout the day. Other predictions suffer the effect of uncertainties of the NWP model when integrated in time $(3 \mathrm{~h}, 6 \mathrm{~h}, \ldots, 24 \mathrm{~h})$. The $Z W D$ results were not significant since they are variable during the 24 hours of prediction. In the first 3 hours of prediction, the 3 hours resolution showed an RMSE of to the ZWD of $1 \mathrm{~mm}$, 
greater than the resolution of 6 hours. The hydrostatic component ( $90 \%$ of the total) achieved an improvement of $1.25 \mathrm{~cm}$ with a resolution of 3 hours, this improvement results in $1.15 \mathrm{~cm}$ in the prediction of the total component with better temporal resolution ( 3 hours).

The assessment of the impact of summer and winter on the quality of temporal resolution has been assessed with the aim of establishing whether the temporal resolutions also suffer variations due to seasonality. The hydrostatic component shows greater variation in the January RMSE with higher values, especially in the NEIA station, which is representative of the majority the stations assessed. The wet component showed better results in the UBA1 coastal station.

The new temporal resolution therefore has an impact mainly on the hydrostatic component, ZHD. The improvement in the spatial and temporal resolution, simultaneously, can be very useful for advances on ZWD predictions quality. Data assimilation in the regional modeling can contribute with better characterization of the atmospheric humidity variability, because this process provides successive correction in the atmospheric state during the model integration. New models are being developed at CPTEC/INPE with hourly prediction, $5 \mathrm{~km}$ of horizontal resolution and data assimilation included, which will be tested in predictions of neutral atmospheric delay. As future works, we will investigate the impact of these improvements, using a long period of data, in the quality of ZTD modeling.

\section{ACKNOWLEDGMENT}

The authors are grateful to CPTEC/INPE for making available NWP data and to FCT-UNESP for making available meteorological data and the GOA-II software used in this research. We also thank Mr. Vinicius Rofatto and the technician Rogério Takeshi Oyama for information support and help in data processing. This work was financed in part by the Coordenação de Aperfeiçoamento de Pessoal de Nível Superior - Brasil (CAPES) - Finance Code 760361. Finally, we wish to thank to the anonymous peer reviewers, from their careful reading, their comments and suggestions, which greatly improve the paper.

\section{AUTHOR'S CONTRIBUTION}

Author Tayná Gouveia developed the study, implementation and data processing, including the tests, data analysis, and writing. All the authors contributed with preparation of draft manuscript, review of the proposed method, discussion of the results, data analysis, paper revision and refinement.

\section{References}

Abreu, P. A. G.; Alves, D. B. M.; Gouveia, T. A. F. 2014. Modelos de Previsão Numérica do Tempo: Aplicação e Avaliação no Posicionamento Absoluto. Revista Brasileira de Cartografia, v.66/3, pp. 681-693.

Alves, D. B. M.; Meneguette Jr, M., Monico, J.F.G. 2005. Utilizando Splines Cúbicas Natural para Atenuação de Erros no Posicionamento GPS. TEMA Tend. Mat. Apl. Comput., 6, No. 2, pp. 197-205.

Alves, D. B. M.; Sapucci, L. F.; Marques, H. A.; Souza, E. M.; Gouveia, T. A. F.; Magario, J. A. 2015. Using a regional numerical weather prediction model for GNSS positioning over Brazil. GPS Solutions (Heidelberg), 15(3), doi 10.1007/ 
s10291-015-0477-x, pp. 253-261.

Dalbelo, L. F. A; Alves, D. B. M; Monico, J. F. G.; Sapucci, L. F. 2006. Minimizando o atraso zenital troposférico no posicionamento DGPS: comparação da modelagem dinâmica com o modelo de Hopfield. Simpósio Brasileiro de Geofísica Espacial e Aeronomia - SBGEA. São José dos Campos - SP.

Gouveia, T. A. F.; Sapucci, L.F.; Monico, J. F.; Alves, D. B. M. 2014. Avaliação robusta da modelagem neutrosférica sobre o território brasileiro baseada em modelos de previsão numérica de tempo da América do Sul. Boletim de Ciências Geodésicas. v. 20, no 3, doi: 10.1590/S1982-21702014000200028, pp. 481-503.

Gregorius, T. 1996. "How it Works...GIPSY-OASIS II". Department of Geomatics University of Newcastle upon Tyne, Canadá.

Hofmann-Wellenhof, B.; Lichtenegger, H. Collins, J. 1992. GPS: Theory and Pratice. 4th. Ed. Austria: Springer-Verlag Wien, 389p.

Li X., Ge M., Zhang H., Wickert J. 2013. A method for improving uncalibrated phase delay estimation and ambiguityfixing in real-time precise point positioning. Ed. J Geod 87, pp. 405-416.

Mesinger, F. 1984. A blocking technique for representation of mountains in atmospheric models. Riv. Meteor. Aeronautica, 44, pp. 195-202.

Mesinger, F.; Chou, S. C.; Gomes, J. L.; Jovic, D.; Bastos, P.; Bustamante, J. F.; Lazic, L.; Lyra, A. A.; Morelli, S.; Ristic, I.; Veljovic. 2012. An upgraded version of the Eta model. Meteorol Atmos Phys,116, doi 10.1007/s00703-012-0182-z, pp. 63-79.

Monico, J. F. G. 2006. GNSS: investigações e aplicações no posicionamento geodésico, em estudos relacionados com a atmosfera e na agricultura de precisão. Projeto FAPESP na modalidade temático. Universidade Estadual Paulista. Presidente Prudente, SP.

Oliveira, A. F.; Alves, D. B. M.; Ferreira, L. D. D. 2014a. Análise de Modelos Troposféricos no Posicionamento Baseado em Redes Usando o Conceito de VRS. Boletim de Ciências Geodésicas. Vol 20/1.

2014b. Avaliação de Diferentes Modelos Troposféricos de Previsão Numérica de Tempo no Posicionamento em Redes. Revista Brasileira de Cartografia, v.66/3.

Sapucci, L. F. 2001. Estimativa do Vapor D'água Atmosférico e a Avaliação da Modelagem do Atraso Zenital Troposférico Utilizando GPS. Dissertação de Mestrado. Faculdade de Ciências e Tecnologia da UNESP, Presidente Prudente.

Sapucci, L. F.; Machado, L. A. T.; Monico, J. F. G. 2004. Modelagem dinâmica do atraso zenital troposférico para America do Sul empregando previsão numérica de tempo. Artigo apresentado no I SIMGEO, Recife.

Sapucci, L. F. 2005. Estimativas do IWV utilizando receptores GPS em bases terrestres no Brasil: Sinergia entre a Geodésia e a Meteorologia. Tese de Doutorado. Faculdade de Ciências e Tecnologia, Universidade Estadual Paulista, Presidente Prudente.

Sapucci, L F., Monico, J. F. G. 2010. Evolução do GNSS meteorologia no Brasil Beneficiando a Previsão Numérica de Tempo sobre a América do Sul. INPE ePrint: sid.inpe.br/mtc-m19@80/2010/08.16.17.36 v1.

Seeber, G. 2003. Satellite Geodesy: Foundations, Methods, and Applications. Berlin, New York: Walter de Gruyter.

Spilker, J. J. JR. 1994. Tropospheric Effects on GPS. American Institute of Aeronautics and Astronautics, vol 1-13, pp. $517-546$. 